\title{
Personality features of obese women in relation to binge eating and night eating
}

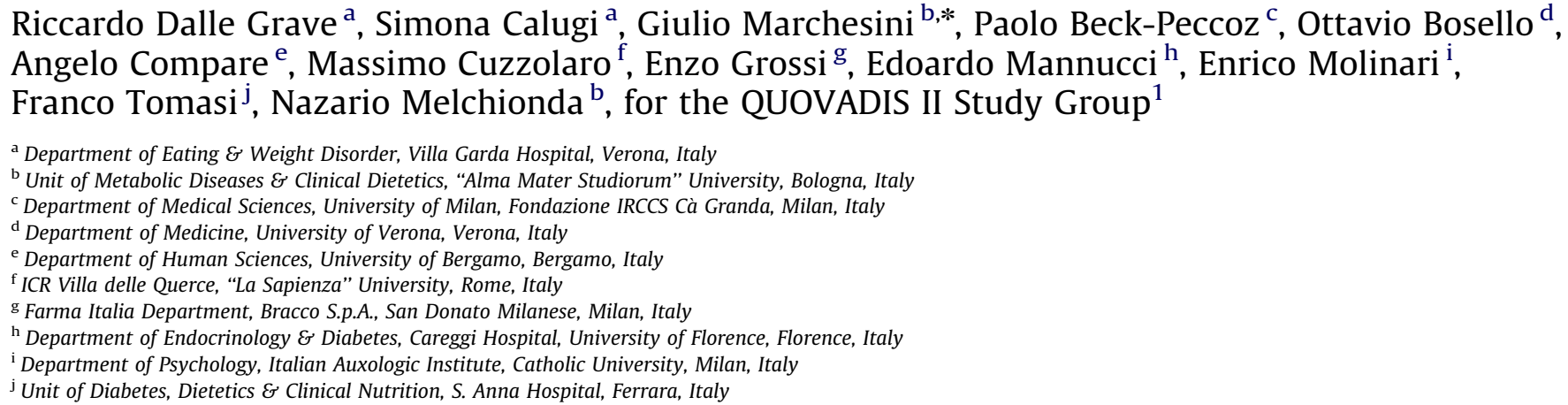

\section{A R T I C L E I N F O}

\section{Article history:}

Received 31 October 2011

Received in revised form

2 September 2012

Accepted 5 September 2012

\section{Keywords:}

Obesity

Personality

Temperament

Character

Depression

Eating disorders

\begin{abstract}
A B S T R A C T
Personality traits can affect eating behaviors, the development of obesity, and obesity treatment failure. We investigated the personality characteristics and their relation with disordered eating in 586 obese women consecutively seeking treatment at eight Italian medical centers (age, $47.7 \pm 9.8$ years) and 185 age-matched, normal weight women without symptoms of eating disorders (Eating Attitude Test $<20$ ). The assessment included anthropometry, the Temperament and Character Inventory (TCI), the Binge Eating Scale (BES) and the Night Eating Questionnaire (NEQ). Logistic regression analyses were carried out in different models with BES score $\geq 27$ and NEQ $\geq 30$ as dependent variables and TCI scores as independent factors. Personality traits of obese individuals included significantly lower selfdirectedness and cooperativeness on TCI. BES and NEQ scores were higher in obese women, and values above the defined cut-offs were present in 77 and 18 cases (14 with high BES), respectively. After controlling for age and BMI, high BES values were associated with high novelty seeking and harm avoidance and low self-directedness, the last two scales being also associated with high NEQ. We conclude that personality traits differ between obese patients seeking treatment and controls, and the presence of disordered eating is associated with specific personality characteristics.
\end{abstract}

(c) 2012 Elsevier Ireland Ltd. All rights reserved.

\section{Introduction}

Disordered eating has been variably associated with specific personality traits (Fassino et al., 2002b; van den Bree et al., 2006), but studies carried out by means of the Karolinska Scales of Personality (Bjorvell et al., 1994; Jonsson et al., 1986; Poston et al.,

\footnotetext{
* Correspondence to: Unit of Metabolic Diseases \& Clinical Dietetics, Alma Mater University of Bologna Policlinico S. Orsola, Via Massarenti, 9 I-40138 BOLOGNA, Italy. Tel.: + 39051 6364889; fax: + 390516364502.

E-mail address: giulio.marchesini@unibo.it (G. Marchesini).

${ }^{1}$ List of participants in the QUOVADIS II Study:s N Villanova, A Suppini, G Marchesini, N Melchionda (Bologna); S Calugi, R Dalle Grave, M Pisano (Garda, VR); E Scalambra, F Tomasi (Ferrara); O Bosello, M Zamboni, A Minniti (Verona); M Cuzzolaro, F Perna, M Sutera, V Trincia (Roma); A Compare, E Molinari (Milano1); S Ciani, B Cresci, E Mannucci, C Rotella (Firenze); P Beck-Peccoz, B Masserini, E Orsi, (Milano-2); E Grossi, G Rivolta (Milano-3).
}

1999) or the Minnesota Multiphasic Personality Inventory (Kolotkin et al., 1987; Martin, 1999) produced conflicting results. Higher scores in monotony avoidance were systematically associated with incapacity to maintain weight loss, but the scale does not help predict outcome in obesity treatment (Poston et al., 1999). These inventories were designed and validated to assess overt pathological personality traits, whereas the inter-individual variation of normal traits may be left undiagnosed because of poor specificity (Sullivan et al., 2007).

Personality traits might be partly responsible for the development of obesity as well as for the failure of obesity treatment (Sullivan et al., 2007), via disordered eating. However, the possible negative role of the social inheritance of obesity and disordered eating on personality changes was also taken into account (Sutin et al., 2011). Whichever the cause and the effect, a precise assessment of personality traits might help identify strategies to improve obesity treatment. 
The Temperament and Character Inventory (TCI) was designed to make a comprehensive evaluation of normal personality (Cloninger et al., 1993, 1994; Svrakic et al., 1993). It is based on a psychobiological model of personality based on seven dimensions divided into temperament and character. Temperament is defined as the partly inherited emotional responses, stable throughout life, mediated by neurotransmitter functioning (Cloninger, 1987) in the central nervous system. It is identified by four dimensions (novelty seeking, harm avoidance, reward dependence and persistence). Character is defined as the sum of personality traits acquired through experience, identified by three dimensions (self-directedness, cooperativeness, self-transcendence).

In individuals with eating disorders, high values of novelty seeking were associated with binge eating or overeating, while low values of novelty seeking with dietary caloric restriction (Brewerton et al., 1993; Bulik et al., 1995b; Fassino et al., 2001, 2004; Kleifield et al., 1994; Waller et al., 1993). Low persistence scores were positively associated with drop-out in a cognitive behavior inpatient treatment for eating disorder (Dalle Grave et al., 2008), whereas high self-directedness was associated with a rapid and sustained response to cognitive behavioral therapy for bulimia nervosa (Bulik et al., 1999).

Only a few data are available on the personality of obese individuals as assessed by the TCI. Obese individuals in the community scored higher in novelty seeking and lower in persistence and self-directedness than non-obese individuals. They also scored lower in reward dependence and cooperativeness than obese individuals of a university weight management program (Sullivan et al., 2007). In a different study, obese patients with binge eating disorder (BED) had lower self-directedness than obese patients without BED (Fassino et al., 2002b), but both groups had higher scores of novelty seeking and harm avoidance, as well as lower scores of cooperativeness and self-directedness compared to controls (Fassino et al., 2002b). Finally, a study in children using the Junior TCI found a trend of lower persistence and higher novelty seeking in overweight compared to normalweight children (Hwang et al., 2006). Limitations of TCI reports in obesity include small sample sizes in the majority of studies and lack of a comprehensive analysis of psychosocial variables in the population (Fassino et al., 2002b; Sullivan et al., 2007).

The present study was aimed to trace personality traits in a large group of obese women seeking treatment at eight Italian medical centers and in a control population without obesity, in order to define a possible specificity of temperament and character in relation to excess body weight. In the obese cohort, personality traits were also evaluated in relation to specific eating disorders frequently associated with obesity.

\section{Materials and methods}

\subsection{QUOVADIS II study planning and protocol}

The QUOVADIS II (QUality of life in Obesity: eVAluation and DIsease Surveillance II) is a purely observational study on personality, psychological well-being, body image and eating behavior set up in 2006 in obese patients seeking treatment at medical centers. It was conducted in eight Italian centers (Verona, Milan, Bologna, Ferrara, Florence, Rome) accredited by the Italian Health Service for the treatment of obesity. After enrollment, subjects were treated along the lines of the specific programs of the Centers, including dieting, cognitive behavioral therapy, and drugs.

The sample study included 586 women with obesity (body-mass index (BMI) $\geq 30 \mathrm{~kg} / \mathrm{m}^{2}$ ), consecutively seeking treatment. All cases, including those with binge eating, were eligible for the study provided they were not on active treatment at the time of enrollment and were in the age range between 25 and 65 years. To ensure that subjects were truly consecutive, the medical record number of the patients was monitored across sites.

The control group consisted of 185 normal weight women (BMI in the range $\left.18.5-24.9 \mathrm{~kg} / \mathrm{m}^{2}\right)$ in the same age range, with a score $<20$ on the Eating Attitude Test (EAT) (to exclude participants with symptoms of eating disorder) (Garner and
Garfinkel, 1979). All subjects of the control group were recruited among relatives and friends of the personnel participating in the study.

Data collection included a detailed case report form and a set of questionnaires for personality, psychological distress and eating behavior disorders. The protocol was approved by the ethical committees of the individual centers, after initial approval by the ethical committee of the coordinating center (Azienda Ospedaliera di Bologna, Policlinico S. Orsola - Malpighi). All participants gave written informed consent to participation. The investigation was carried out in accordance with the latest version of the Declaration of Helsinki.

\subsection{Measures}

\subsubsection{Case report form}

The Case Report Form was filled in by physicians at the time of enrollment by directly interviewing patients.

\subsubsection{Weight and height}

Patients were measured bare-footed and in underwear with a medical balance and a stadiometer. Weight changes were examined from baseline to 12 months.

\subsubsection{Psychosocial assessmen}

Participants with obesity completed a battery of specific questionnaires used to detect personality, psychiatric distress, binge eating, night eating and body image uneasiness. The control subjects completed only the TCI and the EAT.

The TCI is based on a psychobiological model of personality (Cloninger et al., 1994), including four temperament dimensions (novelty seeking, harm avoidance, reward dependence and persistence) and three character dimensions (selfdirectedness, cooperativeness and self-transcendence). Novelty seeking reflects the degree of activation of exploratory activity. Harm avoidance describes the efficiency of the behavioral inhibition system. Reward dependence reflects the maintenance of rewarded behavior. Persistence expresses the maintenance of behavior as resistance to frustration. Self-directedness, cooperativeness and selftranscendence express the degree to which the self is viewed as autonomous, integrated as part of society and as integral part of the universe, respectively. Low self-directedness and cooperativeness are common dimensional patterns across personality disorder subtypes and strong predictors of a diagnosis of DSM axis II disorder (Cloninger et al., 1994). The TCI has good internal consistency (Cloninger et al., 1994; Sato et al., 1999), inter-tester reliability and test-retest reliability (Cloninger et al., 1994). It has been validated in its Italian version (Fassino et al., 2002a).

The Binge Eating Scale (BES) (Gormally et al., 1982) was used to assess the severity of binge eating. Its 16 items examine both behavioral signs (eating large amounts of food) and feeling or cognition during a binge episode (loss of control, guilt, fear of being unable to stop eating). A score $\geq 27$ conventionally serves as a cutoff value for identifying the presence of severe eating disorder, compatible with binge eating disorder, whereas values $\leq 16$ may be used as screening values to exclude binge eating (Greeno et al., 1995).

The Night Eating Questionnaire (NEQ) was used to assess the behavioral and psychological symptoms of the night eating syndrome (NES) (Allison et al., 2008). The NEQ is a 14-item questionnaire that assesses core features (e.g., percentage of calories consumed after dinner and frequency of awakenings and nocturnal ingestions) and associated symptoms of the night eating syndrome (e.g., cravings at night, insomnia, and disordered mood). The total scale exhibited adequate reliability $(\alpha=0.70)$ and a cut-off score of 30 can be used as a screening value predicting a high risk of NES (Allison et al., 2008).

The EAT was limited to the control population to rule out eating disorders (Garner and Garfinkel, 1979). The 26-item EAT (EAT-26) is a standardized measure of symptoms and concerns characteristic of eating disorders; it was the screening instrument used in the 1998 National Eating Disorders Screening Program and has been validated in its Italian version (Dotti and Lazzari, 1998). Studies have shown that values below 20 can reasonably exclude eating disorders, whereas values $\geq 20$ may be referred for a diagnostic interview (Garner et al., 1982).

\subsection{Statistical analyses}

Descriptive statistics are presented by means (standard deviation) for continuous variables and by frequencies (percentages) for discrete variables. The Kolmogorov-Smirnov and Shapiro-Wilk tests indicated that demographic and clinical variables were not normally distributed. The Mann-Whitney test, $\chi^{2}$ test or Kruskal-Wallis test were used for groups comparison, as appropriate.

General linear models were performed to analyze differences between groups, controlling for age and/or BMI.

A stepwise logistic regression analysis, adjusted for age and BMI, was performed in separate models to investigate the association of each personality dimension of the TCI (independent variables) with the presence of clinically significant binge eating (identified by BES values $\geq 27$ as dependent variable) and night eating (identified by NEQ $\geq 30$ ). 
All analyses were performed using SPSS for Windows, Version 15.0. Four sets of variables were analyzed: demographic/anthropometric, BES, NEQ and TCI. Accordingly, the significance limit was set at $p<0.0125$ (Bonferroni correction).

\section{Results}

\subsection{Demographic and clinical variables in obese and control groups}

At baseline the subjects with obesity were characterized by higher scores on the BES and the NEQ and significantly lower selfdirectedness and cooperativeness scores on the TCI, when compared with the control group (Table 1).

\subsection{Clinical characteristics of obese patients}

Obese women had a mean BMI of $38.2 \mathrm{~kg} / \mathrm{m}^{2}$ (S.D. 6.8). Two hundred and thirteen patients (36.3\%) had Class 1 obesity, 187 (31.9\%) Class 2 and 186 (31.7\%) Class 3. The Kruskall-Wallis test showed no differences between the three obesity classes on the total scores of the BES and the NES or on TCI subscales.

\subsection{Binge eating severity and clinical variables in obese patients}

Seventy-seven obese women (13.1\%) were classified as severe binge eaters ( $\mathrm{BES} \geq 27$ ), 137 (23.4\%) were in the intermediate rank (BES values in the range 17-26) and 364 (62.1\%) were in the normal range (BES $\leq 16$ ) (Table 2 ).

Age and BMI did not differ between groups. Women with very high BES scores $(\geq 27)$ also had significantly higher scores on the
NEQ, novelty seeking and harm avoidance than other groups, whereas the group with normal BES values scored significantly higher in the cooperativeness and self-directedness subscales.

Logistic regression analysis, adjusted for age and BMI, showed that $\mathrm{BES} \geq 27$ in the obese population was positively associated with higher NEQ (odds ratio (OR), 1.13; 95\% confidence interval (CI), 1.09-1.17), with deciles of novelty seeking (OR, 1.19; 95\% CI, 1.09-1.31) and harm avoidance (OR, 1.44; 95\% CI, 1.23-1.68), and was negatively associated with deciles of self-directedness (OR, 0.66; 95\% CI, 0.58-0.75). The association was confirmed by linear regression analysis, using BES total score as the dependent variable (not reported in details).

\subsection{Night eating severity and clinical variables in obese patients}

Eighteen obese women (3.1\%) had an NEQ score $\geq 30$. Of note, $17 / 18$ of these participants also had values exceeding the cut-off of 16 on the BES scale, with 14 cases being in the class of severe binge eating ( $\mathrm{BES} \geq 27$ ). A non-parametric analysis comparing participants with high vs. low NEQ scores (Table 3 ) showed that a high NES score was associated with higher scores on the BES, as well as higher score on the harm avoidance and self-directedness subscales of the TCI.

In addition to BES scores (OR, 1.20; 95\% CI, 1.13-1.28), only two TCI subscales were significantly associated with high NES values at logistic regression analysis, adjusted for age and BMI (deciles of harm avoidance: OR, 2.05; 95\% CI, 1.25-3.34, and deciles of self-directedness: OR, 0.74; 95\% CI, 0.59-0.83).

Table 1

Baseline characteristics in obese patients and control group.

\begin{tabular}{|c|c|c|c|c|}
\hline Variables & Obese patients $(N=586)$ & Control group $(N=185)$ & Mann-Whitney test & $p$ value \\
\hline Age (years) & $47.7(9.8)$ & $47.2(10.7)$ & 0.17 & 0.866 \\
\hline Body-mass index $\left(\mathrm{kg} / \mathrm{m}^{2}\right)$ & $38.2(6.5)$ & $22.8(1.7)$ & 20.52 & $<0.001$ \\
\hline Binge Eating Scale (score) & $14.6(9.8)$ & $5.5(5.9)$ & 9.47 & $<0.001$ \\
\hline Night Eating Questionnaire (score) & $12.5(7.6)$ & $10.6(6.0)$ & 2.73 & 0.006 \\
\hline \multicolumn{5}{|c|}{ Temperament and Character Inventory (\%) } \\
\hline Novelty seeking & $47.3(27.0)$ & $45.4(27.8)$ & 1.35 & 0.380 \\
\hline Harm avoidance & $72.6(24.6)$ & $70.7(23.4)$ & 0.88 & 0.178 \\
\hline Reward dependence & $47.6(24.8)$ & $49.4(25.5)$ & 0.83 & 0.408 \\
\hline Persistence & $28.3(24.2)$ & $28.3(25.6)$ & 0.23 & 0.819 \\
\hline Self-directedness & $38.6(27.7)$ & $49.5(28.4)$ & 4.59 & $<0.001$ \\
\hline Cooperativeness & $47.2(23.0)$ & $51.3(22.3)$ & 2.21 & 0.010 \\
\hline Self-transcendence & $27.6(26.2)$ & $26.6(25.9)$ & 0.56 & 0.572 \\
\hline
\end{tabular}

Significant $p$ value $<0.0125$.

Table 2

Binge eating severity and clinical and personality variables in obese patients.

\begin{tabular}{|c|c|c|c|c|c|}
\hline Variables & $\begin{array}{l}\text { No binge eating } \\
(B E S \leq 16)(N=364)\end{array}$ & $\begin{array}{l}\text { Mild binge eating } \\
(\mathrm{BES}, 17-26)(N=137)\end{array}$ & $\begin{array}{l}\text { Severe binge eating } \\
(\mathrm{BES} \geq 27)(N=77)\end{array}$ & $\begin{array}{l}\text { Kruskal- } \\
\text { Wallis test }\end{array}$ & $p$ value \\
\hline Age at baseline & $48.2(9.6)$ & $46.7(9.5)$ & $45.8(10.5)$ & 5.09 & 0.077 \\
\hline BMI $\left(\mathrm{kg} / \mathrm{m}^{2}\right)$ & $37.7(6.3)$ & $39.2(8.0)$ & $39.2(7.0)$ & 5.68 & 0.058 \\
\hline Night Eating Syndrome-Q & $10.4(4.6)$ & $13.9(8.3)^{\mathrm{a}}$ & $20.0(11.6)^{\mathrm{a}, \mathrm{b}}$ & 99.98 & $<0.001$ \\
\hline \multicolumn{6}{|c|}{ Temperament and Character Inventory } \\
\hline Novelty seeking & $44.2(26.6)$ & $49.4(26.7)$ & $58.7(27.0)^{a, b}$ & 18.99 & $<0.001$ \\
\hline Harm avoidance & $68.6(25.4)$ & $76.3(22.5)^{\mathrm{a}}$ & $86.0(18.0)^{a, b}$ & 44.33 & $<0.001$ \\
\hline Reward dependence & $47.7(25.3)$ & $45.5(23.2)$ & $51.3(25.8)$ & 2.62 & 0.270 \\
\hline Persistence & $28.0(23.0)$ & $29.1(26.0)$ & $28.2(26.0)$ & 0.18 & 0.916 \\
\hline Self-directedness & $46.3(27.2)$ & $30.0(23.7)^{\mathrm{a}}$ & $17.5(20.2)^{\mathrm{a}, \mathrm{b}}$ & 89.71 & $<0.001$ \\
\hline Cooperativeness & 50.5 (21.9) & $42.1(23.4)^{\mathrm{a}}$ & $41.9(24.5)^{\mathrm{a}}$ & 17.82 & $<0.001$ \\
\hline Self-transcendence & $27.8(25.6)$ & $26.2(26.2)$ & $29.0(28.9)$ & 0.76 & 0.728 \\
\hline
\end{tabular}

Significant $p$ value $<0.0125$.

${ }^{a} p<0.0125$ vs. no binge eating.

${ }^{\mathrm{b}} p<0.0125$ vs. mild binge eating. 
Table 3

Clinical variables and personality traits in obese patients in relation to night eating.

\begin{tabular}{|c|c|c|c|c|}
\hline Variables & $\begin{array}{l}\text { No night eating } \\
(N=568)\end{array}$ & $\begin{array}{l}\text { Night eating } \\
(N=18)\end{array}$ & $\begin{array}{l}\text { Mann-Whitney } \\
\text { test or } \chi^{2} \text { test }\end{array}$ & $p$ value \\
\hline Age (years) & $47.5(9.8)$ & $50.5(9.6)$ & -1.23 & 0.217 \\
\hline BMI $\left(\mathrm{kg} / \mathrm{m}^{2}\right)$ & $38.2(6.8)$ & $39.0(7.3)$ & -0.40 & 0.689 \\
\hline Binge Eating Scale (score) & $14.0(9.2)$ & $32.4(11.1)$ & -5.60 & $<0.001$ \\
\hline $\mathrm{BES} \geq 27, N(\%)$ & $63(11.3 \%)$ & $14(77.8 \%)$ & 66.56 & $<0.001$ \\
\hline Night Eating Syndrome-Q & $11.6(5.1)$ & $41.7(13.5)$ & -7.45 & $<0.001$ \\
\hline \multicolumn{5}{|c|}{ Temperament and Character Inventory (\%) } \\
\hline Novelty seeking & $47.1(26.9)$ & $52.2(32.2)$ & -0.76 & 0.450 \\
\hline Harm avoidance & $72.0(24.7)$ & $91.2(8.4)$ & -3.45 & 0.001 \\
\hline Reward dependence & $47.7(24.7)$ & $47.1(27.4)$ & -0.05 & 0.959 \\
\hline Persistence & $28.3(24.1)$ & $30.8(25.9)$ & -0.39 & 0.696 \\
\hline Self-directedness & 39.1 (27.7) & $21.5(22.7)$ & -2.63 & 0.008 \\
\hline Cooperativeness & $47.5(23.0)$ & $38.5(21.6)$ & -1.69 & 0.091 \\
\hline Self-transcendence & $27.4(26.0)$ & $36.1(30.9)$ & -1.32 & 0.188 \\
\hline
\end{tabular}

Significant $p$ value $<0.015$

Within the group with $B E S \geq 27$, no significant differences on TCI scores were demonstrated between NES positive cases $(n=14)$ and non-NES cases $(n=63)$.

\section{Discussion}

The principal finding of the study is that peculiar personality characteristics distinguish obese women seeking treatment at Italian medical centers from normal-weight controls. A few of these characteristics are amplified by the presence of high scores on psychometric testing compatible with binge eating and night eating.

The study has several strengths. First, it presents data of a large and heterogeneous sample of obese patients seeking treatment in eight obesity medical centers scattered throughout Italy. This population is expected to be representative of the total population of obese women not seeking bariatric surgery. Second, it evaluates personality by means of the $\mathrm{TCI}$, which is more reliable than other measures of personality, providing a reproducible assessment of inter-individual variability in personality traits in subjects without specific psychopathology (Cloninger et al., 1993). Third, the study provides a measure of personality traits in the presence of disordered eating.

At baseline, obese patients have lower self-directedness and cooperativeness than controls, as previously reported in obese individuals from clinical samples (Fassino et al., 2002b). Selfdirectedness measures internal organization and the ability to set and pursue meaningful goals (Cloninger et al., 1994). Low scores in self-directedness might be a personality characteristic of obese patients implicated in their difficulty to set weight loss goals and to maintain weight control behaviors (Sullivan et al., 2007). Selfdirectedness was also the only personality variable that predicted treatment outcome at 1-year follow-up in patients with bulimia nervosa treated by cognitive behavior therapy (Bulik et al., 1998). Low scores in cooperativeness suggest relational difficulties in obese individuals seeking treatment (Fassino et al., 2002b) that might also jeopardize the patient-therapist relationship during the treatment program. These results need to be confirmed in the treatment of obesity before personality traits may be used in the clinical setting.

We could only partly confirm other differences in personality characteristics of obese individuals observed in other studies (Fassino et al., 2002b; Sullivan et al., 2007). Higher levels of novelty seeking had already been identified in both an Italian and a U.S. population sample (Fassino et al., 2002b; Sullivan et al., 2007). In our analysis high novelty seeking was associated with a higher risk of high BES scores. High harm avoidance was similarly identified in the large U.S. population sample (Sullivan et al., 2007), whereas in our analysis it was only associated with a much higher risk of disordered eating (both high BES and high NEQ scores). Obesity is a very heterogeneous condition, and cultural or social differences, as well as specific settings, may make the difference. The recruitment of obese subjects from eight centers in different Italian areas was intended to overcome this bias.

Also in our setting, no differences in personality were observed between the three classes of obesity severity, suggesting that personality characteristics do not have a relevant role in determining the severity of obesity (Fassino et al., 2002b).

Our data confirm previous observations in clinical samples supporting the notion that disordered eating in obese patients seeking treatment is associated with distinctive personality characteristics (Fassino et al., 2002b; Sullivan et al., 2007). In addition to low self-directedness, we also found high scores of novelty seeking and harm avoidance in female subjects with obesity and high BES scores, as already found in binge-eaters independent of overweight or obesity (Grucza et al., 2007). Individuals with high novelty seeking scores tend to be thrill seekers, easily bored, impulsive and inclined to avoid monotony: a combination of features that might lead these individuals to binge to avoid boredom (Sullivan et al., 2007). On the contrary, lower scores on novelty seeking have been associated with a healthy dietary control and a cognitive control of food intake (Bjorvell et al., 1985; Jacobs and Wagner, 1984). High scores on novelty seeking have also been associated with worse weight loss outcome in patients treated with behavioral therapy (Sullivan et al., 2007) and may also be a negative factor on weight loss outcome in the presence of binge eating. A high score on harm avoidance is a personality characteristic also observed in patients with bulimia nervosa (Bulik et al., 1995a). This temperamental feature might be responsible for the tendency to lose control over food intake and for weight gain in obese patients (Fassino et al., $2002 b$ ). High scores on harm avoidance are also typical of patients with mood disorders (Sato et al., 2001; Svrakic et al., 1992), and correlate with alterations in the serotonin systems (Cloninger and Svrakic, 2009), conditions both associated with binge eating (Araujo et al., 2010; Steiger, 2004).

An original finding is the demonstration of peculiar personality traits in obese women with night eating, a result never reported in the literature. In addition, obese patients with high scores on night eating and on binge eating had very similar personality traits, and the large majority of NES positive cases were included in the subgroup with severe binge eating, an observation also made in the previous study (Napolitano et al., 2001). 
The presence of high NEQ scores might identify a subgroup of binge-eaters suffering from even more severe psychological burden. This result, however, needs confirmatory studies due to the low number of NES positive cases identified in our population. Finally, the frequent association of night eating and binge eating suggests that the evidence-based treatments for binge eating disorder and bulimia nervosa (i.e., cognitive behavior therapy and interpersonal psychotherapy) (National Collaborating Centre for Mental Health, 2004) might also be effective in night eaters.

In eating disorder patients, some TCI personality features are influenced by weight loss-induced changes in depression and eating disorder psychopathology (Dalle Grave et al., 2009; Fabricatore et al., 2011; Karlsson et al., 2007). Future studies should evaluate if the personality characteristics observed in our obese female patients with high scores on binge and night eating might be influenced by these psychopathological variables or merely by obesity or by the alterations of the serotonin system observed both in individuals with binge eating (Araujo et al., 2010; Steiger, 2004) and with night eating (Lundgren et al., 2009).

The study has additional weaknesses. First, personality and eating disorder variables were evaluated by self-reported questionnaires, instruments that tend to overestimate the prevalence of psychopathology (Fairburn and Beglin, 1994). Second, our findings are restricted to obese individuals seeking treatment in a medical setting and do not provide any information on the large number of obese individuals in the community who do not seek treatment or who seek help in non-medical settings.

Personality characteristics have previously been shown to predict outcome and attrition in the behavioral and surgical treatment of obesity (De Panfilis et al., 2006, 2008). Future studies should investigate whether and, possibly, how much personality characteristics might influence compliance to treatment and weight loss outcome in response to specific behavioral treatment programs (e.g., individual vs. group care). It would also be interesting to evaluate if weight loss may change some personality characteristics (namely, the character domains) and whether adapting treatment to specific personality traits may help improve outcome. Finally, it should be investigated if strategies derived from the cognitive behavior therapy for bulimia nervosa might also improve the outcome of obesity management. This treatment is indeed associated with decreased harm avoidance and increased self-directedness (Anderson et al., 2002) and similar strategies might be reproduced in the treatment of obesity. These data are pivotal to determine whether measures of personality are worth being included in the comprehensive assessment of obese individuals.

\section{Acknowledgments}

The QUOVADIS II study was supported by an unrestricted grant from Farma Italia Department, Bracco S.p.A., San Donato Milanese, Italy.

\section{References}

Allison, K.C., Lundgren, J.D., O’Reardon, J.P., Martino, N.S., Sarwer, D.B., Wadden, T.A., Crosby, R.D., Engel, S.G., Stunkard, A.J., 2008. The Night Eating Questionnaire (NEQ): psychometric properties of a measure of severity of the Night Eating Syndrome. Eating Behaviors 9, 62-72.

Anderson, C.B., Joyce, P.R., Carter, F.A., McIntosh, V.V., Bulik, C.M., 2002. The effect of cognitive-behavioral therapy for bulimia nervosa on temperament and character as measured by the temperament and character inventory. Comprehensive Psychiatry 43, 182-188.

Araujo, D.M., Fonseca, G.D., Nardi, A.E., 2010. Binge eating disorder and depression: a systematic review. World Journal of Biological Psychiatry 11, 199-207.

Bjorvell, H., Aly, A., Langius, A., Nordstrom, G., 1994. Indicators of changes in weight and eating behaviour in severely obese patients treated in a nursing behavioural program. International Journal of Obesity \& Related Metabolic Disorders 18, 521-525.

Bjorvell, H., Edman, G., Rossner, S., Schalling, D., 1985. Personality traits in a group of severely obese patients: a study of patients in two self-chosen weight reducing programs. International Journal of Obesity 9, 257-266.

Brewerton, T.D., Hand, L.D., Bishop Jr., E.R., 1993. The Tridimensional Personality Questionnaire in eating disorder patients. International Journal of Eating Disorders 14, 213-218.

Bulik, C.M., Sullivan, P.F., Carter, F.A., McIntosh, V.V., Joyce, P.R., 1999. Predictors of rapid and sustained response to cognitive-behavioral therapy for bulimia nervosa. International Journal of Eating Disorders 26, 137-144.

Bulik, C.M., Sullivan, P.F., Joyce, P.R., Carter, F.A., 1995a. Temperament, character and personality disorder in bulimia nervosa. Journal of Nervous and Mental Disease 183, 593-598.

Bulik, C.M., Sullivan, P.F., Weltzin, T.E., Kaye, W.H., 1995b. Temperament in eating disorders. International Journal of Eating Disorders 17, 251-261.

Bulik, C.M., Sullivan, P.F., Joyce, P.R., Carter, F.A., McIntosh, V.V., 1998. Predictors of 1 -year treatment outcome in bulimia nervosa. Comprehensive Psychiatry 39, $206-214$.

Cloninger, C.R., 1987. A systematic method for clinical description and classification of personality variants. A proposal. Archive of General Psychiatry 44, 573-588.

Cloninger, C.R., Svrakic, D.M., 2009. Personality disorders. In: Sadock, B.J., Sadock, V.A., Ruiz, P. (Eds.), Kaplan and Sadock's Comprehensive Textbook of Psychiatry. Lippincott Williams \& Wilkins, Philadelphia, PA, pp. 2197-2239.

Cloninger, C.R., Svrakic, D.M., Przybeck, T.R., 1993. A psychobiological model of temperament and character. Archive of General Psychiatry 50, 975-990.

Cloninger, C.R., Svrakic, D.M., Przybeck, T.R., Wetzel, R.D., 1994. The Temperament and Character Inventory (TCI): A Guide to Its Development and Use. Center for Psychobiology of Personality, St. Louis, MO.

Dalle Grave, R., Calugi, S., Brambilla, F., Marchesini, G., 2008. Personality dimensions and treatment drop-outs among eating disorder patients treated with cognitive behavior therapy. Psychiatry Research 158, 381-388.

Dalle Grave, R., Calugi, S., Corica, F., Di Domizio, S., Marchesini, G., 2009 Psychological variables associated with weight loss in obese patients seeking treatment at medical centers. Journal of the American Dietetic Association 109, 2010-2016.

De Panfilis, C., Cero, S., Torre, M., Salvatore, P., Dall'Aglio, E., Adorni, A., Maggini, C. 2006. Utility of the temperament and character inventory (TCI) in outcome prediction of laparoscopic adjustable gastric banding: preliminary report. Obesity Surgery $16,842-847$.

De Panfilis, C., Torre, M., Cero, S., Salvatore, P., Dall'Aglio, E., Marchesi, C., Cabrino, C. Aprile, S., Maggini, C., 2008. Personality and attrition from behavioral weightloss treatment for obesity. General Hospital Psychiatry 30, 515-520.

Dotti, A., Lazzari, R., 1998. Validation and reliability of the Italian EAT-26. Eating \& Weight Disorders 3, 188-194.

Fabricatore, A.N., Wadden, T.A., Higginbotham, A.J., Faulconbridge, L.F., Nguyen, A.M., Heymsfield, S.B., Faith, M.S., 2011. Intentional weight loss and changes in symptoms of depression: a systematic review and meta-analysis. International Journal of Obesity (London) 35, 1363-1376.

Fairburn, C.G., Beglin, S.J., 1994. Assessment of eating disorders: interview or selfreport questionnaire? International Journal of Eating Disorders 16, 363-370.

Fassino, S., Abbate-Daga, G., Amianto, F., Leombruni, P., Boggio, S., Rovera, G.G. 2002a. Temperament and character profile of eating disorders: a controlled study with the Temperament and Character Inventory. International Journal of Eating Disorders 32, 412-425.

Fassino, S., Leombruni, P., Piero, A., Abbate-Daga, G., Amianto, F., Rovera, G., Rovera, G.G., 2002b. Temperament and character in obese women with and without binge eating disorder. Comprehensive Psychiatry 43, 431-437.

Fassino, S., Abbate-Daga, G., Piero, A., Leombruni, P., Rovera, G.G., 2001. Anger and personality in eating disorders. Journal of Psychosomatic Research 51, 757-764.

Fassino, S., Amianto, F., Gramaglia, C., Facchini, F., Abbate-Daga, G., 2004. Temperament and character in eating disorders: ten years of studies. Eating \& Weight Disorders 9, 81-90.

Garner, D.M., Garfinkel, P.E., 1979. The Eating Attitudes Test: an index of the symptoms of anorexia nervosa. Psychological Medicine 9, 273-279.

Garner, D.M., Olmsted, M.P., Bohr, Y., Garfinkel, P.E., 1982. The Eating Attitudes Test: psychometric features and clinical correlates. Psychological Medicine 12, 871-878.

Gormally, J., Block, S., Daston, S., Rardin, D., 1982. The assessment of binge eating severity among obese persons. Addictive Behaviors 7, 47-55.

Greeno, C.G., Marcus, M.D., Wing, R.R., 1995. Diagnosis of binge eating disorder: discrepancies between a questionnaire and clinical interview. International Journal of Eating Disorders 17, 153-160.

Grucza, R.A., Przybeck, T.R., Cloninger, C.R., 2007. Prevalence and correlates of binge eating disorder in a community sample. Comprehensive Psychiatry 48, $124-131$.

Hwang, J.W., Lyoo, I.K., Kim, B.N., Shin, M.S., Kim, S.J., Cho, S.C., 2006. The relationship between temperament and character and psychopathology in community children with overweight. Journal of Developmental \& Behavioral Pediatrics 27, 18-24.

Jacobs, S.B., Wagner, M.K., 1984. Obese and nonobese individuals: behavioral and personality characteristics. Addictive Behaviors 9, 223-226.

Jonsson, B., Bjorvell, H., Levander, S., Rossner, S., 1986. Personality traits predicting weight loss outcome in obese patients. Acta Psychiatrica Scandinavica 74 384-387. 
Karlsson, J., Taft, C., Ryden, A., Sjostrom, L., Sullivan, M., 2007. Ten-year trends in health-related quality of life after surgical and conventional treatment for severe obesity: the SOS intervention study. International Journal of Obesity (London) 31, 1248-1261.

Kleifield, E.I., Sunday, S., Hurt, S., Halmi, K.A., 1994. The Tridimensional Personality Questionnaire: an exploration of personality traits in eating disorders. Journal of Psychiatric Research 28, 413-423.

Kolotkin, R.L., Revis, E.S., Kirkley, B.G., Janick, L., 1987. Binge eating in obesity: associated MMPI characteristics. Journal of Consulting and Clinical Psychology $55,872-876$

Lundgren, J.D., Amsterdam, J., Newberg, A., Allison, K.C., Wintering, N., Stunkard, A.J., 2009. Differences in serotonin transporter binding affinity in patients with major depressive disorder and night eating syndrome. Eating \& Weight Disorders $14,45-50$.

Martin, L.F., 1999. The biopsychosocial characteristics of people seeking treatment for obesity. Obesity Surgery 9, 235-243.

Napolitano, M.A., Head, S., Babyak, M.A., Blumenthal, J.A., 2001. Binge eating disorder and night eating syndrome: psychological and behavioral characteristics. International Journal of Eating Disorders 30, 193-203.

National Collaborating Centre for Mental Health (2004). Eating disorders. Core interventions in the treatment and management of anorexia nervosa, bulimia nervosa and related eating disorders. Clinical Guideline 9, The National Institute for Clnical Excellence, London.

Poston II, W.S., Ericsson, M., Linder, J., Nilsson, T., Goodrick, G.K., Foreyt, J.P., 1999 Personality and the prediction of weight loss and relapse in the treatment of obesity. International Journal of Eating Disorders 25, 301-309.
Sato, T., Hirano, S., Narita, T., Kusunoki, K., Kato, J., Goto, M., Sakado, K., Uehara, T., 1999. Temperament and Character Inventory dimensions as a predictor of response to antidepressant treatment in major depression. Journal of Affective Disorders 56, 153-161.

Sato, T., Narita, T., Hirano, S., Kusunoki, K., Goto, M., Sakado, K., Uehara, T., 2001 Factor validity of the Temperament and Character Inventory in patients with major depression. Comprehensive Psychiatry 42, 337-341.

Steiger, H., 2004. Eating disorders and the serotonin connection: state, trait and developmental effects. Journal of Psychiatry and Neuroscience 29, 20-29.

Sullivan, S., Cloninger, C.R., Przybeck, T.R., Klein, S., 2007. Personality characteristics in obesity and relationship with successful weight loss. International Journal of Obesity (London) 31, 669-674.

Sutin, A.R., Ferrucci, L., Zonderman, A.B., Terracciano, A., 2011. Personality and obesity across the adult life span. Journal of Personality and Social Psychology 101, 579-592.

Svrakic, D.M., Przybeck, T.R., Cloninger, C.R., 1992. Mood states and personality traits. Journal of Affective Disorders 24, 217-226.

Svrakic, D.M., Whitehead, C., Przybeck, T.R., Cloninger, C.R., 1993. Differential diagnosis of personality disorders by the seven-factor model of temperament and character. Archive of General Psychiatry 50, 991-999.

van den Bree, M.B., Przybeck, T.R., Cloninger, C.R., 2006. Diet and personality: associations in a population-based sample. Appetite 46, 177-188.

Waller, D.A., Gullion, C.M., Petty, F., Hardy, B.W., Murdock, M.V., Rush, A.J., 1993. Tridimensional Personality Questionnaire and serotonin in bulimia nervosa. Psychiatry Research 48, 9-15. 